\title{
CONDUTA CLÍNICA PROFISSIONAL QUANTO AO USO E DESCARTE DE PONTAS DIAMANTADAS
}

\author{
Andrea Nóbrega Cavalcanti Doutorado em Clínica Odontológica pela \\ Universidade Estadual de Campinas. Professora \\ da Escola Bahiana de Medicina e Saúde Pública.
}

\author{
Poliana Ramos Braga Santos
}

Graduada em Odontologia, mestranda em

Odontologia e Saúde, Faculdade de

Odontologia, Universidade Federal da Bahia.

\author{
Jamille Carmo Oliveira Estudante de graduação, Faculdade de \\ Odontologia, Universidade Federal da Bahia.
}
Daniel Lima Ramos Mestre, Faculdade de Odontologia, Universidade Federal da Bahia.

\author{
Céres Mendonça Fontes Mestre, Curso de Odontologia da Escola \\ Bahiana de Medicina e Saúde Pública e \\ Faculdade de Odontologia da Universidade \\ Federal da Bahia.
}

\begin{abstract}
Resumo
Objetivo. O objetivo deste estudo foi verificar a opinião de cirurgiões-dentistas a respeito das causas de desgaste e dos critérios utilizados para o descarte de pontas diamantadas. Metodologia. 114 cirurgiões dentistas responderam um questionário auto-explicativo que foi posteriormente submetido à análise descritiva dos resultados obtidos. Resultados. Segundo os resultados obtidos, tem-se quea maior parte dos participantes considera que amálgama e esmalte são as estruturas que mais determinam o desgaste das pontas diamantadas $(60 \%$ e $29 \%$, respectivamente). Além disso, a maioria indicou que os processos de esterilização aceleram este envelhecimento (78\%). As principais razões para odescarte dos instrumentos foram: escurecimento(79\%), aumento do tempoe força necessária para desgaste das estruturas (79\%),diminuição da quantidade de diamantes da ponta ativa $(78 \%)$ quebra da ponta ativa $(73 \%)$ e presença de resíduo entre os grânulos de diamante (49\%). Conclusão. Necessidade de maior conhecimento em relação aos processos de esterilização e quantidade de utilizações das pontas diamantadas devido a sua predominância na prática clinica.
\end{abstract}

Palavras-chave: Instrumentos Odontológicos; Diamante.; Eficiência; Esterilização.

\section{PROFESSIONAL CLINICAL ATTITUDE REGARDING THE USAGE AND DISPOSAL OF DIAMOND BURS}

\begin{abstract}
Purpose.The purpose of this study was to check dentists' opinions about reasons of wear and the criteria used for disposal of diamond burs. Methods.114 dentists answered a self-explanatory questionnaire, whichwas subsequently submitted to a descriptive analysis of results. Results. According to the data gathered, it was noted that most of participants considers that amalgam and enamel are the primary cause of diamond burs'wear $(60 \%$ and $29 \%$, respectively). Furthermore, most individuals have indicated that sterilization processes accelerated the aging $(78 \%)$. The primary causes of diamond burs disposal: darkening (79\%),increase in timeand strength necessary to wear structures (79\%),decrease in the concentration of diamonds on the tip of the bur $(78 \%)$, and presence of residues $(49 \%)$.Conclusion.Moreknowledgein sterilization processes and quantity of diamond points uses is need due to its prevalence in clinical practice.
\end{abstract}

Keywords: Dental Instruments; Diamond; Efficiency; Sterilization. 


\section{INTRODUÇÃO}

As pontas diamantadas foram introduzidas no mercado desde o século XIX. ${ }^{(1)}$ Estes instrumentos são formados por uma haste metálica e por uma ponta ativa com formatos e dimensões variadas. Durante o processo de fabricação, grânulos de diamante (substância abrasiva) são fixadospor eletrodeposição de níquel ahaste metálicacom a finalidade de aumentar a sua superfície de corte. ${ }^{(2-4)}$

Apesar do surgimento de novas tecnologias como o preparo cavitário com a abrasão a ar, o laser de Er:YAG e as pontas diamantadas ultrassônicas, o corte de estrutura dental utilizando pontas diamantadas ainda predomina na prática clínica do cirurgião dentista. ${ }^{(5-7)}$ Estes instrumentos rotatórios são empregados comdiversas finalidades, incluindo preparoscavitáriosde restaurações diretas e indiretas e acabamento e polimento de materiais restauradores. $^{(2)}$

Alguns trabalhos relatam a diminuição da eficiência de desgaste das pontas diamantadas devido à perda das partículas de diamante, alterando a forma do instrumento. ${ }^{(4,5)}$ Dentre os fatores capazes de alterar a eficiência das pontas ainda podem ser citados os consecutivos preparos, as repetidas esterilizaçõese o acúmulo de detritos. ${ }^{(1,5)} \mathrm{O}$ desgaste do instrumento ainda pode variar de acordo com sua marca comercial, granulação e densidade dos diamantes da ponta ativa, tipo de refrigeração da peça de mãoe substrato a ser desgastado. ${ }^{(1,8)}$

Apesar de estudos in vitro demonstrarem a perda de eficiência das pontas diamantadas causada por diferentes fatores, pouco se sabe a respeito do real conhecimento e conduta clínica profissionaldocirurgião-dentista frente ao envelhecimento progressivo destes materiais.Desta forma, este estudo teve o objetivo de verificar a opinião de cirurgiõesdentistas a respeito das causasde desgastee dos critérios utilizados para descarte de pontas diamantadas.

\section{METODOLOGIA}

Para a realização deste trabalho foi utilizada uma amostra por conveniência, compostade cirurgiões dentistas clínicos e especialistas, presentes no XV Congresso Internacional de Odontologia da Bahia (XV CIOBA), realizado em Outubro de 2008, na cidade de Salvador, Bahia. Os participantes assinaram o termo de consentimento para 
realização da pesquisa e preencheram um questionário auto-aplicativocontendo perguntas a respeito da área de atuação profissional, ano de formatura, opinião sobre estimativa de uso, vida útil e estruturas que influenciariam o desgaste das pontas diamantadas, além de critérios utilizados para a substituição destes instrumentos. Os quesitos respondidos eram objetivos, categorizando, dessa forma, os resultados obtidos.

Um total de 113 questionários foi recolhido durante o congresso. As informações presentes nos questionários foram tabuladas e submetidas à análise descritiva percentual de seus resultados.

\section{RESULTADOS}

Dos 113 participantes deste estudo, 40\% classificaram-se como clínicos gerais e $60 \%$ como especialistas. Dentre as especialidades, Dentística, Prótese e Odontopediatria foram as mais citadas. Com relação ao ramo de atividade dos participantes, tem-se que 5\% atuam apenas no serviço público, $60 \%$ em clínicas particulares e $35 \%$ em ambas as atividades. A média de tempo de formatura dos profissionais foi de 15 anos. A maior parte da amostra foi composta por profissionais do sexo feminino $(61 \%)$.

As respostas relacionadas à conduta dos participantes frente à substituição das pontas diamantadas estão descritas na Tabela 1. Os métodos indicados pelos participantes para descarte das pontas diamantadas estão apresentados na Figura 1.A quantidade de utilizações clínicas da ponta diamantada foi proposta como um dos itens, porém, nenhum entrevistado selecionou este item como critério de descarte 
Cavalcanti et al. Conduta Clínica Profissional Quanto ao Uso e Descarte de Pontas Diamantadas

Tabela 1 - Distribuição das respostas dos participantes relacionadas ao desgaste clínico das pontas diamantadas

\begin{tabular}{|c|c|c|c|}
\hline Questão & Padrão de resposta & $\mathbf{N}$ & $\%$ \\
\hline Você acha que é possível estimar quantas vezes uma & Não & 77 & 68 \\
\hline ponta ou broca foi usada na prática clínica? & Sim & 36 & 32 \\
\hline \multirow{4}{*}{$\begin{array}{l}\text { Em sua opinião, qual destas estruturas acelera o } \\
\text { envelhecimento das pontas diamantadas mais } \\
\text { rapidamente? }\end{array}$} & Esmalte & 33 & 30 \\
\hline & Amálgama & 68 & 60 \\
\hline & Dentina & 7 & 6 \\
\hline & Resina & 5 & 4 \\
\hline \multirow{4}{*}{$\begin{array}{l}\text { Em sua opinião, qual a vida útil de uma ponta } \\
\text { diamantada? }\end{array}$} & Até 10 utilizações & 42 & 37 \\
\hline & Mais de 20 utilizações & 14 & 13 \\
\hline & Entre 10 e 20 utilizações & 40 & 35 \\
\hline & Não é possível estimar & 17 & 15 \\
\hline \multirow{2}{*}{$\begin{array}{l}\text { Você acha que os métodos de esterilização aceleram o } \\
\text { envelhecimento das pontas? }\end{array}$} & Não & 25 & 22 \\
\hline & Sim & 88 & 78 \\
\hline
\end{tabular}

Figura 1- Distribuição das principais razões indicadas para descarte das pontas diamantadas, em porcentagem

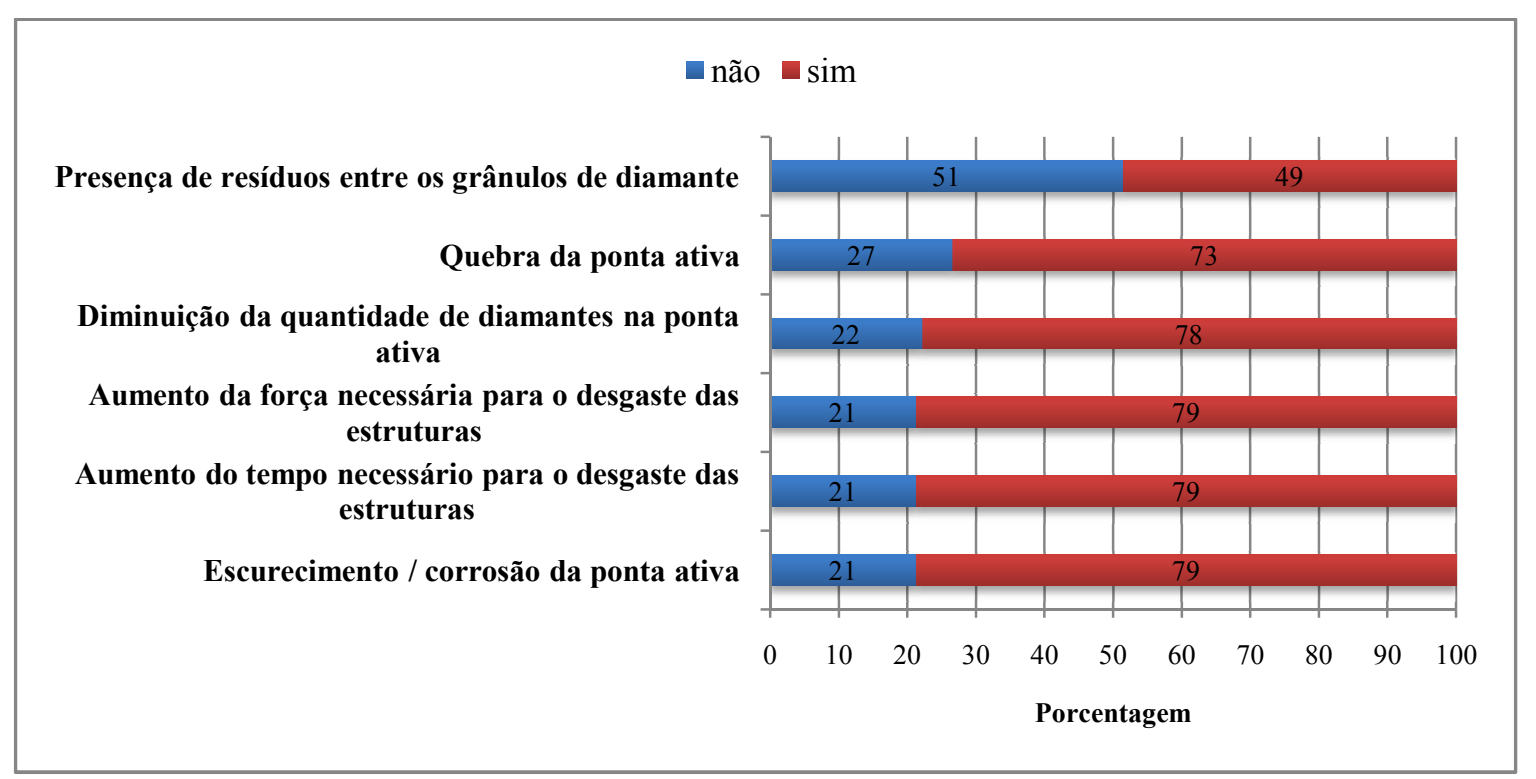

\section{DISCUSSÃO}

A eficiência de desgaste de uma ponta diamantada pode ser definida como a sua capacidade em remover o máximo de estrutura dental no mínimo período de tempo, com menor esforço e sem a produção de calor friccionalcapaz de lesaro complexo dentinopulpar. ${ }^{(1,3,9,10)} \mathrm{Na}$ prática clínica, associar o possível desgaste da ponta diamantada com o 
comprometimento de sua eficiência pode ser fundamental para a segurança dos procedimentos.

Segundo alguns autores, a vida útil destes instrumentos pode variar devido a fatores diversos que estão relacionados tanto a fabricação do instrumento quanto ao próprio substrato a ser desgastado. ${ }^{(1,2,10,11)}$

Em relação ao desgaste dos substratos por pontas diamantadas, a literatura aponta melhor eficiência de desgaste em dentina do que em esmalte, possivelmente devido à maior dureza deste último. Um estudo, ${ }^{(1)}$ utilizando diferentes marcas de pontas diamantadas, concluiuque os desgastes realizados em porção cervicalde dentes bovinosforam maiores que os realizados em porção incisal, evidenciando a maior dificuldade do desgaste em tecidos mais duros(maior quantidade de esmalte).

Em outro estudo, ${ }^{(11)}$ os autores compararam, por meio de fotomicrografias, o desgaste de pontas diamantadas após o uso em esmalte humano e esmalte bovino. O esmalte humano, por apresentar resistência ligeiramente maior que o bovino, provocou diminuição $7 \%$ mais rápida do número de diamantes das pontas, com perda de eficiência após 48 minutos de uso quando comparado ao esmalte bovino (perda de eficiência após 60 minutos de uso).

Estes achados estão de acordo com a opinião da maioria dos cirurgiões dentistas entrevistados. Apenas 6\% relataram que a dentina provocou envelhecimento acelerado das pontas diamantadas enquanto, a maioria atribuiuum maior envelhecimento do instrumento aoamálgama (60\%) e ao esmalte (29\%).

É importante ressaltar que aeficiência de desgaste das estruturas por pontas diamantadas podem estar intimamente relacionados à granulação dos diamantes que constituem a extremidade ativa da ponta. ${ }^{(5,12)}$ Um estudo prévio ${ }^{(3)}$ verificou que as pontas diamantadas com melhor eficiência foram aquelas em que, durante o processo de fabricação, os grãos de diamante apresentavam espaçamentos maiores e mais homogêneos. Grãos menos cristalinos e mais friáveis, característicos de alguns tipos de diamantes, geram maiores arestas de corte no topo dos grãos abrasivos, melhorando a capacidade de remoção de material. Desta maneira, conhecer o método de fabricação utilizado pelo fabricante pode ser um importante critério utilizado pelo cirurgião-dentista na seleção do instrumento.

Quanto àfrequência de uso das pontas diamantadas, a literatura demonstra que o uso em excesso, sem substituição, promove maior desgaste e perda de eficiência clínica do instrumento. ${ }^{(4,10)}$ Pontas novas apresentam partículas de diamantes com ângulos vivos em toda a superfície. ${ }^{(12)}$ Já, em pontas desgastadas, os diamantes deslocam-se tornando aparente a base 
do instrumento e expondo crateras correspondentes aos locais onde os diamantes estavam depositados. ${ }^{(5)}$ A perda da eficiência de desgaste ou corte do instrumento pode induzir o operador a exercer maior pressão de corte na tentativa de compensar a ineficiência da ponta, podendo provocar injúrias ao complexo dentino-pulpar. ${ }^{(4)}$

Um estudo prévio demonstrou que o aumento do tempo deuso está diretamente relacionado com a perda gradativa da eficiência de desgaste das pontas diamantadas. ${ }^{(1)}$ Os autores observaram que algumas marcas comerciais perdem eficiência mais rapidamente do que outras, sendo possível notar a perda de eficiência depois do desgaste de dois fragmentos de esmalte bovino submetidos a 15 ciclos de $3 \mathrm{~mm}$ de extensão. Uma possível explicação para este desgaste diferencial das pontas diamantadas seria o tipo de processo de fabricação do instrumento por cada fabricante. Durante este processo, a seleção dos grãos de diamantes, do material constituinte da haste, do agente aglutinador e do processo de fixação do grão a haste, por este agente aglutinante podem influenciar na perda das partículas de diamante e, conseqüentemente, na eficácia do instrumento. ${ }^{(3,8)}$ Com resultados semelhantes, outros autoresobservaramdiferenças na perda gradativa da capacidade de corte nas marcas analisadas; e detectaram diferenças significativas no tempo de confecção dos sulcos a partir do nono desgaste (12 sulcos de $5 \mathrm{~mm}$ de comprimento). ${ }^{(10)}$

No presente estudo, quando questionados sobre a vida clínica útil da ponta diamantada, a maioria dos cirurgiões dentistas opinou que a mesma vai até 10 utilizações (37\%) e entre 10 e 20 utilizações (35\%). Tal fato não está em concordância com a literatura, a qual sugere o uso de $3^{(1)}$ a $10^{(10)}$ vezes do instrumento sem comprometer a sua eficiência de desgaste. A relevância deste uso excessivo das pontas diamantadas torna-se ainda mais preocupantequando associada a outro dado encontrado neste estudo: a maioria dos entrevistados (68\%) não se acha capaz de estimar quantas vezes uma ponta diamantada foi utilizada na sua prática clinica.

Outro fator que poderá influenciar na eficiência das pontas diamantadas e,consequentemente, no padrão de desgaste destas é a quantidade de ciclos de esterilização aplicados. ${ }^{(13,14)}$ Após o uso clínico, restos dentais, sangue, saliva, microorganismos e materiais restauradoresse alojam entre as partículas de diamante do instrumento, contaminando as pontas diamantadas, comprometendo sua eficiência e potencializando o risco de infecção cruzada. $^{(3,11)}$ Desta forma, a limpeza e a desinfecção das mesmas são fundamentais na prática clínica. 
Em um estudo prévio, ${ }^{(3)}$ foi analisada a eficiência de desgaste de pontas diamantadas de diferentes fabricantes após métodos de desinfecção química com glutaraldeído à $2 \%$ e derivado da amônia à $0,2 \%$. Os autores concluíram que os agentes desinfetantes não apresentaram influência estatisticamente significante na capacidade desgaste da ponta diamantada.

Entretanto, a desinfecção não pode ser confundida com esterilização, pois a primeira não elimina todos os microrganismos presentes no instrumental, apenas reduz o seu número, diminuindo o risco de infecção. ${ }^{(8)}$ Entretanto, no processo de esterilização, todas as formas de microrganismos presentes são destruídas.A agressividade dos processos de esterilização e de determinadas soluções de desinfecção podem afetar odesempenho dos instrumentos rotatórios, pois tais processos geram degradação estrutural que diminui a eficiência e longevidade das pontas diamantadas. ${ }^{(15)}$ Gureckis et al. ${ }^{(16)}$ afirmaram que repetidos ciclos de desinfecção afetam a matriz de fixação dos diamantes à haste, com diminuição do suporte da partícula, perda da mesma e, consequente, redução da capacidade de corte.

O achado final do presente estudo diz respeito ao método de descarte das pontas diamantadas. De acordo com a opinião dos cirurgiões dentistas entrevistados, o descarte das pontas diamantadas deve ocorrer por razões como: escurecimento/corrosão da ponta ativa (79\% das respostas), aumento do tempo e força necessários para o desgaste das estruturas (79\%), diminuição da quantidade de diamantes na ponta ativa (78\%), quebra da ponta ativa (73\%), presença de resíduo entre os grânulos de diamante (49\%).É importante ressaltar que a quantidade de utilizações clínicas da ponta diamantada não foi proposta por nenhum entrevistado como um critério de descarte. Como a maioria das evidências científicas determina que uso excessivo de uma mesma ponta diamantada é a principal razão do seu envelhecimento, perda da capacidade de corte e consequente insucesso clínico, pode-se sugerir que o tempo de uso seria um método mais confiável e seguro para indicar o descarte dos instrumentos.

\section{CONCLUSÃO}

De acordo com as limitações do presente estudo, foi possível confirmar o conhecimento dos cirurgiões dentistas em relação às estruturas e situações clínicas que mais degradam as pontas diamantadas. Entretanto, verificou-se que os profissionais não souberam 
estimar quantas vezes fizeram o uso de uma mesma ponta diamantada na prática clínica e utilizam métodos baseados na experiência para indicar o descarte destes instrumentos.

\section{Agradecimentos}

Os autores agradecem à organização do XV Congresso Internacional da Bahia pela disponibilização do espaço para realização deste estudo, e à KG Sorensen, pelo auxílio à impressão dos questionários.

\section{REFERÊNCIAS}

1. Ciccone JC, Souza WCS, Torres CP, Chinelatti MA, Palma-Dibb RG. Avaliação da Eficiência de Desgaste de Pontas Diamantadas. RGO 2004; 52(4):211-214.

2. Bianchi ARR, Freitas CA, Bianchi EC, Silva EJ, Cezar FAG. Possibilidade do emprego das pontas diamantadas na odontologia moderna. RevBrasEngBiomed 1999; 15(1-2):39-48.

3. Silva RHBT, Pimenta FB, Pita APG, Pereira JM. Pontas Diamantadas: Eficiência de Corte Após Limpeza. RGO 2002; 50(4):225-230.

4. Borges AB, Cavalcanti BN, Araújo MAM. Avaliação do desgaste de pontas diamantadas e sua influência na infiltração marginal de restaurações de resina composta. CiencOdontol Bras 2003;6(1):36-43.

5. Siegel SC, Fraunhofer AV. CuttigEfficiency of three diamond bur grit sizes. JADA 2000;131:1706-1710.

6. Kreidler MAM, Oliveira-Junior OB. A tecnologia de abrasão a ar na Odontologia restauradora. RevOdontol UNESP. 2008; 37(3):249-252.

7. Lima LM, Motisuki C, Lopes BMV, Santos-Pinto L. Resistência de união e microinfiltração em restaurações de resina composta em função do instrumento de corte. RevOdontol UNESP 2011, 40(6): 317-324.

8. Freitas VMC, Roriz VC, Chiavini PCR, Young AAA, Bozzo RO, Telles EZ. Desinfecção e Esterilização em Ortodontia. RGO. 2005; 53(4):335-338.

9. Soares PBF, Mamede OS, Lemes EV, Castro CG, Fernandes Neto AJ, Soares CJ. Análise da qualidade de instrumentos rotatórios utilizados por acadêmicos de odontologia.

RevOdontol UNESP2008;35(3):149-156.

10. Freire CBRCM, Freitas CA, Francisconi AZS. Avaliação do Desempenho de Pontas Diamantadas. RevFacOdontol Bauru 1996;4(1-2):17-23. 
11. Pinelli LAP, Marcelo CC, Pita APG, Silva RHBT, Guaglianoni DG. Estudo fotomicrográfico do desgaste de pontas diamantadas em diferentes substratos. CiencOdontolBras 2004;7(4):60-66.

12. Bianchi EC, Aguiar PR, Monici RD, Bianchi ARR, Freitas CA. Características da Estrutura Cristalina de Grãos Diamantados. Revciênctecnol 2002;10(19):31-38.

13. Bianchi EC, Silva EJ, Cesar FAG, Aguiar AR, Bianchi ARR, Freitas CA, Riehl H. Aspectos microscópicos da influencia dos processos de esterilização em pontas diamantadas. Material Research 2003; 6(2):203-210.

14. Tavares da Silva RHB, Miranda AF, Pimenta FB, Pita APG, Pinelli LAP. Efeito da desinfecção química sobre a eficiência de corte de pontas diamantadas. RevOdontol UNESP 2002;31(2):259-268.

15. Borges CF, Magne P, Pfender E, Heberlein J. Dental diamond burs made with a new technology. J Prosthet Dent 1999;82(1):73-79.

16. Gureckis KM, Burgess JO, Schwart RS. Cutting effectiveness of diamond instruments subjected to cyclic sterilization methods. J Prosthet Dent 1991;66(6):721-726. 